Article

\title{
The Financial Crisis and Co-Movement of Global Stock Markets-A Case of Six Major Economies
}

\author{
Yonghong Jiang ${ }^{1,2}$, Mengmeng $\mathrm{Yu}^{3}$ and Shabir Mohsin Hashmi ${ }^{4, *}$ \\ 1 Institute of Finance, Jinan University, Guangzhou 510632, China; ojyh@jnu.edu.cn \\ 2 Department of Economics, University of Wisconsin-Eau Claire, 105 Garfield Avenue, WI 53711, USA \\ 3 Finance Department, Jinan University, Guangzhou 510632, China, jndxymm@163.com \\ 4 International School, Jinan University, Guangzhou 510632, China \\ * Correspondence: thashmi@jnu.edu.cn
}

Academic Editors: Xiang Li, Jian Zhou, Hua Ke and Xiangfeng Yang

Received: 14 November 2016; Accepted: 6 February 2017; Published: 13 February 2017

\begin{abstract}
This paper investigates the impact of recent financial crisis on six major stock markets during the three periods. To measure the impact of the crisis on different stock markets, we have applied a vector auto-regression (VAR) model and conducted Granger causality tests. The data used in this study, consists of time series of daily stock market indices at closing time, in terms of local currency units of the world's six major stock markets which were affected during the financial crisis, while the sample period was divided into several sub-periods. The main objectives of the research was to discover the degree of interdependence of the six stock markets and trace out the Granger causality relationships and dynamic responses of one market to in another in innovation, and to make a comparison on the degree of the co-movements in three periods, namely, the pre-crisis period, crisis period, and post-crisis periods. The results suggest that the financial crisis has reinforced the interdependence relationship of global stock markets. However, general co-movements of global stock markets persist even after the crisis and still remained stronger in some economies.
\end{abstract}

Keywords: stock market co-movement; VAR model; Granger causality test; impulse response; financial crisis

\section{Introduction}

With the collapse of Lehman Brothers in New York in 2008, turmoil in financial markets around the world began. There were massive failures of financial institutions and a staggering collapse in asset values in developed and developing countries alike. The financial crisis has crashed the US stock markets, thus sending a wave of uncertainty around the globe. Table 1 highlights the collapse of major financial institutions with important events.

This paper investigates the co-movement of global stock markets through vector auto-regression (VAR) model before, during and after the 2008 financial crisis in six major stock markets, namely the US, UK, mainland China, Hong Kong, Japan and Germany. The purpose of this paper is to provide an in-depth analysis with special emphasis on comparison on international co-movements among financial markets in pre-crisis, during the crisis and post-crisis periods. Additionally, this paper addresses the following issues:

(i) Does one market's movement significantly affect another market's movement?

(ii) How much of the movements in one stock market can be explained by innovations in other market?

(iii) How rapid are the price movements in one market transmitted to other markets? 
(iv) Does the relationship of causality, explanation of innovation and pace of transmission of price movement differ, before, during and after the financial crisis?

Rest of the paper is organized as follows. Section 2 offers the literature review and covers the methodology, VAR model and the Granger causality test. The data description and empirical findings are presented in Section 3, while Section 4 provides the summary and conclusion.

Table 1. Collapse of financial institutions with major events.

\begin{tabular}{|c|c|}
\hline Month & Events \\
\hline \multicolumn{2}{|l|}{2007} \\
\hline April & $\begin{array}{l}\text { New Century Financial Corp-which was the second largest subprime mortgage corporation in USA, has filed a plea } \\
\text { for bankruptcy protection. }\end{array}$ \\
\hline July & Standard and Poor's downgraded mortgage bonds which caused shocks in global stock markets. \\
\hline \multirow{5}{*}{ August } & Bear Steams Cos-the fifth largest investment bank in the US had announced the liquidation of its two hedge funds. \\
\hline & American Home Mortgage announced bankruptcy. \\
\hline & The indices of global stock markets plummeted. \\
\hline & Many banks and financial companies in America, France, England and Switzerland suffered heavy losses. \\
\hline & $\begin{array}{l}\text { The Federal Reserve and central banks in Europe injected capital to save the financial markets. Over } \$ 320 \text { billion } \\
\text { were injected in less than } 48 \mathrm{~h} \text { all over the world. }\end{array}$ \\
\hline October & Merrill Lynch, Nomura Securities and Swiss Bank Corporation suffered massive losses. \\
\hline November & Housing prices fluctuated notably in America and other parts of the world. \\
\hline \multicolumn{2}{|l|}{2008} \\
\hline March & Bear Steams filed bankruptcy protection then was acquired by Morgan Stanley. \\
\hline \multirow{4}{*}{ September } & Lehman Brothers and Merrill Lynch filed bankruptcy; the latter was acquired by the Bank of America. \\
\hline & Goldman Sacks and Morgan Stanley announced to be bank holding company. \\
\hline & Fannies Mae and Freddie Mac were taken over by American government. \\
\hline & The Federal Reserve rescued American International Group Inc. when it was on the brink of bankruptcy. \\
\hline \multicolumn{2}{|l|}{2009} \\
\hline January & American government declared $\$ 138$ billion emergency bailout when the stock price of Citibank hit the bottom. \\
\hline \multirow{2}{*}{ March } & $\begin{array}{l}\text { General Motors, Chrysler and Ford Motor were on the verge of bankruptcy clearly indicating that the financial crisis } \\
\text { is taking its tool. }\end{array}$ \\
\hline & $\begin{array}{l}\text { Dow Jones Index reached its lowest point since April 1997. Its market value reduced to less than half in } 18 \text { months. } \\
\text { The index then increased with oscillation. }\end{array}$ \\
\hline September & Many of Economies started showing some recovery. \\
\hline
\end{tabular}

\section{Literature Review and Methodology}

\subsection{Research on Correlation among Stock Market}

There has been a wealth of literature covering the topic of financial crisis and its associate linkages to stock markets. In the past, most studies have focused on the individual countries, among the exceptions of Michel (2011) [1] and Liow (2012) [2] who have found that international stock prices were co-integrated. The relationship among national stock markets has been analyzed since 1970s, such as Granger and Morgenstern (1970), Agmon (1973), and Hilliard (1979) [3-5]. These studies generally found that the interdependence of share price movements is much less pronounced among countries than within a country. After the so-called October Crash of 1987, when the stock markets in the world collapsed in a row, more studies on the co-movement among stock markets have been geared up. Since then, many practitioners as well as academicians became more interested in analyzing the co-movement between stock markets before, during and after the crash periods. Some of the reference studies concerning this topic are Malliaris and Urrutia (1992) [6], as well as Ang (2002) [7], which generally found no significant correlation among the major stock markets in the world before the 1987 crisis, but it drastically increased during the crash and then sharply declined after the crash. 
As the financial markets integration goes deeper, the correlations between the stock markets become stronger. Along with the deepening of research on stock market correlation, there derives various theories about the stock markets correlation. The channels include the exchange rate of the stock market theory and investor's expectation theory. Exchange rate theory shows that exchange rate transmission mechanism will work on the stock market in a certain extent, and the investor's expectation theory claims that investors have similar expectations which reflect on their investment. The relevant stock market correlation theories includes international capital asset pricing theory, arbitrage pricing theory, efficient market theory, behavioral finance theory, and the information spillover effect. Both international capital asset pricing theory and arbitrage pricing theory come from the law of one price, which says that the price of financial assets in different markets should be equal, and they explain the correlation between the stock market from the asset pricing aspects. The efficient market theory says that stock prices will fully reflect the information it contained, so the flow of information between different stock markets lead to the correlation between the stock markets. Behavioral finance theory asserts that the investors' subjective factors contribute to the process, which says the investor's asset allocation preferences, the scope of investor's securities investment, and herding effect do a lot to securities market linkages. Information spillover effects argues that since the opening times of stock market are different in different countries and regions, the information of the stock market will, in turn, reflect on their assets price, which leads to the correlation between different stock markets. The above theory suggests that different stock markets do carry a certain degree of correlation.

Carefully examination of international stock market movements in recent years suggests that there exists a substantial degree of interdependence among national stock markets. Evidence presented in previous studies reinforced that financial crisis that; influenced financial markets in different regions or even globally can enhance this interdependence. Aloui, Aïssa and Nguyen (2011) [8] did research on global stock markets in 2011 and confirmed that during the financial crisis, extreme co-movement exist in all markets of the U.S, China, India, Russia and Brazil. However, according to Dajcman et al. (2012) [9], the co-movement dynamics across the stock markets of England, Germany, France and Austria are time-varying, and the global financial crisis did not uniformly increase the degree of co-movements across stock market returns unanimously.

Empirical studies on the pre-crisis and crisis periods of the global financial crisis such as Lee and Jeong (2014) [10], have indicated that the level of market integration between Europe and other global stock markets had temporally increased during the global financial crisis. However, the level returned to its pre-crisis level in the post-crisis era. Furthermore, studies of Liow (2005) [11] and Celic (2012) [12] stated that the financial crisis does not enhance the interdependence of Chinese market and foreign markets alike.

Many previous studies have also indicated that the U.S. stock market presents co-movement relationship with other developed and developing markets. The co-movement among global stock markets would change when a crisis emerged. This paper endeavors to measure those responses and analyze three-stage sample periods concerning the co-movement before, during and after the financial crisis of 2007.

\subsection{Methodology}

Based on above theory, in this paper, we use vector-regressive (VAR) model to solve the co-movement for global stock markets during the financial crisis period. Since the variance decomposition requires estimates of infinite-horizontal expectations. The basic VAR methodology from Lee (2014) [10] is applied, but extended in various directions. Since VAR contributes a lot to the study of co-movements, this paper offers some of the theoretical introduction related to the VAR method. 


\subsubsection{The VAR Model}

Sims developed the vector autoregressive analysis (VAR). The VAR model examined six variables based on daily rate of return of the sample stock markets. The VAR model is expressed as:

$$
x_{t}=\phi_{0}+\sum_{s=1}^{p} \phi_{s} x_{t-s}+\varepsilon_{t}
$$

where $x_{t}=\left(x_{1 t}, x_{2 t}, \ldots, x_{m t}\right)^{T}$ is an $m \times 1$ vector of jointly determined dependent variables. $\phi_{0}$ and $\phi_{s}$ are, respectively, $m \times 1$ and $m \times m$ matrices of coefficients, $p$ is the lag length, and $\varepsilon_{t}$ is the $m \times 1$ column vector of forecast errors of the best linear predictor of $x_{t}$ using all the past $x_{s}$. The $i$ th and $j$ th component of $\phi_{s}$ measure the direct effect that a change in the return to the $j$ th market would have on the $i$ th market in $s$ periods.

When rewrites a VAR $(p)$ model into a linear function of the past innovations, and use the Cholesky decomposition to transform the innovations so that the resulting components are uncorrelated, one can obtain:

$$
x_{t}=\sum_{i=0}^{\infty} \psi_{i}^{*} b_{t=i}
$$

where $\psi_{0}^{*}=L$ and $\psi_{i}^{*}=\psi_{i} L$. $L$ is a lower triangular matrix such that $\sum=L G L^{T}$, where $G$ is a diagonal matrix and the diagonal elements of $L$ are unity $b_{t}=L^{-1} \varepsilon_{t}$.

\subsubsection{Granger Causality Test}

When a stationary time series $\left\{x_{t}\right\}$ has an impact on another time series $\left\{y_{t}\right\}$ in the Granger causality sense, we can characterize this using the following equation:

$$
Y_{t}=\delta_{0}+\sum_{i=1}^{m} \partial_{i} X_{t=i}+\sum_{i=1}^{m} \beta_{i} Y_{t=i}+\mu_{t}
$$

If null hypothesis Ho: $\sum_{i=1}^{m} \partial_{i}=0$ is rejected, $\left\{x_{t}\right\}$ is said to Granger-cause $\left\{y_{t}\right\}$.

To estimate the coefficients of above equations, we try to get the error sum of squares of the restricted model and full model using following equation:

$$
S=\frac{\left(S S R_{R}-S S R_{F}\right) / m}{S S R_{F} /(T-2 m-1)}
$$

where $S S R_{R}$ and $S S R_{F}$ are the residual sum of squares of the restricted model and full model respectively. $T$ is the sample period; $m$ is the length of the lag; $S$ is known to have a distribution of $F(m, T-2 m-1)$.

\section{Results and Discussion}

\subsection{Description of the Data}

Since our study is mainly focused on the co-movement of stock markets during different time periods, we have divided the time into three intervals (before, during, and after). In order to cover all periods and trace out their co-relations, we have used different datasets. When a significant event happens, generally, stock price swings. According to Klaassen (2002) [13], who insisted to select the time period to make it consistent with the result using events selection, we have summarize several significant events from 2007 to 2009 in Table 1, which makes it clear how many companies bankrupted on 8th August 2007.We know that was beginning of the crisis. According to the findings of Chang et al. (2012) [14] using a Markov regime switching model, this paper chooses 19 months starting from 9 August 2007 to 6 March 2009 assuming the sample period of the financial crisis. On 6 March 2009, the Dow Jones Index reached to its lowest point since April 1997. Its market value reduced to half in less than 18 months. The index then increased with oscillations. We regarded these as the ending point of the crisis period, and after that, the index started to recover. While, 
the second period begins from 9 August 2007 to 6 March 2009, this paper chooses 11 July 2010, the day when President Obama officially signed the Dodd-Frank Wall Street Reform and Consumer Protection Act-the most significant financial regulatory reform since the 1930s, as the last day of the post-crisis period, which means the third interval instigates from 7 March 2009 to 11 July 2010. Chang et al. (2012) [14] stated that 14 June 2006, on which the US stock market began booming with large volume, is chosen to be the beginning date of pre-crisis period.

In theory, using different time periods in different markets will increase the accuracy from an empirical aspect. However, when processing the data, for a particular market, it is difficult to use a standard scale that measures the end of the crisis. Additionally, the unreasonable segment will magnify the error. In addition, with the integration of information and the closer connection of the global economy, the differences of the duration of financial crisis impact are not large. By looking at the GDP and the unemployment rate of sample countries, it is evident that the unemployment rate went up to several countries in 2009. This further validates that the impact of the crisis varies due to time interval for different markets. To understand the impact of the crisis during different times, we have divided the sample period into the following categories:

(i) Pre-crisis period: 16 months from 14 June 2006 to 8 August 2007.

(ii) Crisis period: 20 months from 9 August 2007 to 6 March 2009.

(iii) Post-crisis period I: 16 months from 7 March 2009 to 11 July 2010.

In order to measure the correlation of sample markets, we have selected the major stock markets of six countries. The stock names are Standard and Poor's 500 (U.S.), Financial Times and London Stock Exchange (UK), Germany DAX index (Germany), Nikkei 225 (Japan), Hang Seng (Hong Kong), and SSE Composite Index (mainland China). These stock market indices are transformed to daily rates of return, which are then used in our VAR analysis. The returns are calculated by taking the log difference of the stock prices on two consecutive trading days. The numbers of observations are 267, 361, and 319 for these three sub-periods, respectively. Potential problems associated with any non-stationary series in the original stock market indices can be alleviated by using the transformed data.

Given that national stock markets are generally operating in different time zones with different opening and closing times, their rate of return on a given calendar day may, in fact, represent the returns realized over different real time periods. For the purpose of interpreting the empirical results later on, it is important to know the operating hours of one market relative to other markets in a real time scale. This information is provided in Table 2 which shows the opening and closing times of the six stock exchanges in New York time.

Table 2. Opening and closing times of major stock exchanges in New York Time.

\begin{tabular}{ccc}
\hline Exchange & Opening Time- & Closing Time \\
\hline China $^{*}$ & 8:30 p.m.- & 2:00 a.m. \\
Hong Kong * & 8:30 p.m.- & 3:00 a.m. \\
Japan * & 7:00 p.m.- & 1:00 a.m. \\
Germany & 2:30 a.m.- & 10:00 a.m. \\
UK & 4:30 a.m.- & 10:00 a.m. \\
USA & 9:30 a.m.- & 3:30 p.m. \\
\hline
\end{tabular}

Note: Asterisk $(*)$ denotes previous day in New York time.

Table 2 shows all three Asian-Pacific stocks were closed when the New York Stock Exchange (NYSE) was opened on the same day. On the other hand, the Frankfurt exchange and London Stock Exchange were closed half an hour after the NYSE opened. Due to time difference, different stock markets had different opening and closing times. Hence, using the daily rate of return directly will cause calculation errors. In order to solve this problem, we have made several changes on the data processing. For the three Asian markets, since they were closed when U.S. stock market opened, so for 
these three markets in Asia, we have selected the yield of the second day as the yield of the day before. For the UK and Germany markets, these two markets have not closed when the US stock market was opened, which means we do not need to change the daily yield of return. Through this method of calculation, we have tried to resolve the time lag problem.

\subsection{Preliminary Discussion}

Table 3 shows the contemporaneous correlations of the residual returns among the six stock markets. The residuals or innovations represent abnormal stock market returns that were not predicted based on the information reflected in the past returns. The contemporaneous correlations of the residual returns reflect the degree to which new information producing an abnormal return in one market is shared by another foreign market in the same calendar day.

Table 3 elucidates that the financial crisis strengthens the contemporaneous correlations, as twelve out of fifteen pairs of residual correlation relationship increased during the crisis period. Furthermore, seven out of fifteen pairs present lower correlations in the post-crisis period, while eight pairs give even higher correlations. These eight pairs of relationships are the residual correlations between US, UK and Germany, and residual correlations between China and the rest of the six markets. The high contemporaneous correlation among US, UK, and Germany reflects that UK and Germany pay more attention to the U.S. economy even after the financial crisis. It is also argued that the turmoil of the financial crisis transferred to Europe later when the European debt crisis emerged three years after the financial crisis.

Table 3. Correlation matrix of residual returns.

\begin{tabular}{|c|c|c|c|c|c|c|}
\hline & USA & UK & GERMANY & HONG KONG & JAPAN & CHINA \\
\hline \multicolumn{7}{|c|}{ Panel (A) pre-crisis period: 14 June 2006-8 August 2007} \\
\hline USA & 1.000 & 0.592 & 0.619 & 0.163 & 0.153 & 0.170 \\
\hline UK & & 1.000 & 0.861 & 0.328 & 0.303 & 0.148 \\
\hline GERMANY & & & 1.000 & 0.299 & 0.299 & 0.138 \\
\hline $\begin{array}{l}\text { HONG } \\
\text { KONG }\end{array}$ & & & & 1.000 & 0.486 & 0.318 \\
\hline JAPAN & & & & & 1.000 & 0.212 \\
\hline CHINA & & & & & & 1.000 \\
\hline \multicolumn{7}{|c|}{ Panel (B) crisis period: 9 August 2007-6 March 2009} \\
\hline USA & 1.000 & 0.656 & 0.697 & 0.387 & 0.338 & 0.038 \\
\hline UK & & 1.000 & 0.863 & 0.522 & 0.528 & 0.114 \\
\hline GERMANY & & & 1.000 & 0.507 & 0.540 & 0.120 \\
\hline $\begin{array}{l}\mathrm{HONG} \\
\mathrm{KONG}\end{array}$ & & & & 1.000 & 0.697 & 0.423 \\
\hline JAPAN & & & & & 1.000 & 0.196 \\
\hline CHINA & & & & & & 1.000 \\
\hline \multicolumn{7}{|c|}{ Panel (C) post-crisis period: 6 March 2009-21 July 2010} \\
\hline USA & 1.000 & 0.750 & 0.746 & 0.364 & 0.287 & 0.231 \\
\hline UK & & 1.000 & 0.902 & 0.476 & 0.363 & 0.259 \\
\hline GERMANY & & & 1.000 & 0.377 & 0.269 & 0.169 \\
\hline $\begin{array}{l}\text { HONG } \\
\text { KONG }\end{array}$ & & & & 1.000 & 0.614 & 0.548 \\
\hline JAPAN & & & & & 1.000 & 0.328 \\
\hline CHINA & & & & & & 1.000 \\
\hline
\end{tabular}

Note: the panel shows the co-relations among countries in different time periods.

Through the data, we can easily verify that the British and German stock markets have the highest correlation, which stands at 0.861 . Plausible reason might be the geographical location and economic and trade linkages between the two larger economies of the region. Additionally, the correlation 
between America and Germany, the correlation between America and Britain ranks second and third respectively. For the mainland Chinese market, its stock market correlation with other countries is low, but after the crisis, we have seen an increased correlation between the Chinese stock market and other countries. For China, the degree of openness is not high, because the Chinese stock market is supervised by the government to a certain extent which makes it less likely to be affected by other countries, therefore, not affected evenly by the financial crisis.

The overall higher co-movement in global stock markets than in the pre-crisis period may reflect that more common shock was shared by these stock markets during the crisis. Credit derivatives decreased in value, housing prices plummeted, exchange rates fluctuated, massive hedge funds transferred risk globally, and so on. Furthermore, panic among individual investors also stimulated the co-movement of global stock markets. In addition, the dramatic increase of residual correlation between the U.S. and Japan may be partly explained by the large flow of Japanese hot money which, resultantly, aggravated the co-movement between the US and Japanese stock markets.

During the crisis period, the influence of mainland Chinese stock market was relatively low which can be indicated by the minor increase of residual correlation to other markets. According to Aloui, Aïssa, and Nguyen (2011) [8], the potential of internal demand for expansion and domestic consumption, supported by the high growth rate of the Chinese economy, could have provided a cushion against slower growth in the global economy and reduced the strong dependence of the Chinese market on external markets, such as the European Union, and USA. As a result, the Chinese economy was less vulnerable to external shocks.

Conversely, during the crisis period, the Hong Kong stock market shared significant abnormal return of shock with the Chinese market. However, in the post-crisis period, China presents the largest co-movement with other stock markets. Instead of strengthening the co-movement mechanics during the crisis, the financial crisis has yielded more influence on China in the post-crisis period. The financial crisis made Chinese market more integrated with the global economy.

In line with the general observations explained above, the contemporaneous correlation of the US with three Asian-Pacific markets was low. The relatively high correlation between the US, UK and Germany is partially due to the time difference as the US market operates one half hour before the closure of London Stock Exchange and Frankfurt exchange.

\subsection{The Results of Granger Causality Test}

The contemporaneous correlation provides information about the co-movement, especially according to new information of stock markets, while it gives no information about the direction of influence. In order to determine whether one market affects a foreign market significantly, the Granger causality test is applied. Table 4 shows the result of the Granger causality tests for USA, UK, Germany, Hong Kong, Japan, and Mainland China in the three periods respectively.

Except China, Granger causalities from the US to other countries were significant for the entire sample period. This implies that, to some extent, many economies largely depend on the US economy and evenly respond when the US economy is in trouble. The strong causality relationship was also found in the UK, Germany, Japan and Hong Kong. It is worth mentioning that the causality relationship was insignificant in case of Hong Kong and Japan, while these two markets showed a high correlation of residual returns in the later section. The contradiction can be explained by significant causality relationship for the US to these two markets correspondingly.

The results present sixteen causal relations during the pre-crisis period. During the crisis period, there were twenty causal relations. However, the number was down to fifteen in the post-crisis period.

While, during the crisis period, the US, UK, and Germany all showed Granger causality relations on mainland China, meaning these largest markets exerted more influence on the Chinese market during the crisis and the influence persisted after the crisis, as well. A bi-directional Granger causality relation was found in Germany and the UK. Granger causality was significant in both directions, which was often termed as a feedback relation. Moreover, the Shanghai Stock Exchange 
was significantly causal force for Hong Kong Stock Exchange and the Tokyo Stock Exchange, but the causality relationship fades away after the crisis.

Table 4. Granger causality test results.

\begin{tabular}{|c|c|c|c|c|}
\hline \multirow{2}{*}{\multicolumn{2}{|c|}{ Direction of Causality }} & Pre-Crisis & Crisis & Post-Crisis \\
\hline & & 14 June 2006-8 August 2007 & 9 August 2007-6 March 2009 & 6 March 2009-21 July 2010 \\
\hline \multirow{5}{*}{ UK } & U.S. & 0.63 & 2.06 & $3.78 *$ \\
\hline & Japan & $26.91^{* * *}$ & $94.78^{* * *}$ & $9.74^{* * *}$ \\
\hline & Hong Kong & 0.03 & 0.71 & 1.47 \\
\hline & Germany & $32.30 * * *$ & $50.02^{* * *}$ & $19.44^{* * *}$ \\
\hline & China & $7.18^{* *}$ & $3.24 *$ & 1.01 \\
\hline \multirow{5}{*}{ U.S. } & UK & $82.69^{* * *}$ & $67.05^{* * *}$ & $57.74^{* * *}$ \\
\hline & Japan & $5.69^{* *}$ & $3.05 *$ & 0 \\
\hline & Hong Kong & $79.26^{* * *}$ & $153.15^{* * *}$ & $160.89^{* * *}$ \\
\hline & Germany & $2.87^{*}$ & $2.93 *$ & 0.98 \\
\hline & China & 0.04 & $22.69^{* * *}$ & $7.39 * * *$ \\
\hline \multirow{5}{*}{ Japan } & UK & 0.63 & $4.19^{* *}$ & $9.21 * * *$ \\
\hline & U.S. & 0.98 & $4.13^{* *}$ & $3.01 *$ \\
\hline & Hong Kong & $7.38^{* * *}$ & 1.16 & 0.14 \\
\hline & Germany & $42.30^{* * *}$ & $42.68^{* * *}$ & $20.01 * * *$ \\
\hline & China & $4.70^{* *}$ & 1.46 & 0.66 \\
\hline \multirow{5}{*}{ Hong Kong } & Germany & $40.32 * * *$ & $63.62^{* * *}$ & $98.03 * * *$ \\
\hline & China & 0.63 & 1.18 & 0.05 \\
\hline & UK & 0.9 & $20.46^{* * *}$ & $5.13^{* *}$ \\
\hline & U.S. & $3.85 *$ & 0.09 & 0.45 \\
\hline & Japan & $33.34^{* * *}$ & $40.73^{* * *}$ & $22.40 * * *$ \\
\hline \multirow{5}{*}{ Germany } & UK & $6.90^{* *}$ & $4.52 * *$ & 0.01 \\
\hline & U.S. & $48.96^{* * *}$ & $86.71^{* * *}$ & $100.30^{* * *}$ \\
\hline & Japan & 0.07 & 1.44 & 0.45 \\
\hline & Hong Kong & $3.47 *$ & $17.29^{* * *}$ & $3.61 *$ \\
\hline & China & 0.51 & 0.03 & 0.11 \\
\hline \multirow{5}{*}{ China } & UK & 0.13 & $6.41^{* *}$ & $3.80 *$ \\
\hline & U.S. & 0.13 & $11.31^{* * *}$ & 0.16 \\
\hline & Japan & 0.5 & 0.48 & 0.27 \\
\hline & Hong Kong & 0.93 & $3.92 *$ & 0.15 \\
\hline & Germany & 0.56 & 1.21 & 0.38 \\
\hline
\end{tabular}

Notes: ${ }^{*}$ denotes rejection at a $10 \%$ level, respectively; ${ }^{* *}$ denotes rejection at a $5 \%$ level, respectively; ${ }^{* *}$ denotes rejection at a $1 \%$ level, respectively.

In the post-crisis period, the UK showed a feedback relationship with the US market. It is observed that the structure of causality in the post-crisis period was different from that in the pre-crisis period. Some causality relations from other markets to the US markets become insignificant, which indicates that the financial crisis has reinforced the influence of the US market as an originator rather than a follower.

On the other hand, before the crisis, Hong Kong and Japanese markets had feedback relationships with the US, UK and Germany. However, these six bi-lateral relationships disappeared after the crisis. This is in line with the decreased residual correlation of these five markets in the post-crisis period.

The findings of our research are comparable to those of Malliaris and Urrutia (1992) [6] which claim that the co-movement among stock markets of other countries have increased significantly during the crisis. However, one major difference in the findings is that in the Malliaris and Urrutia study, in the post-crash period, no co-movements were found, while our study confirms strong co-movements in the post-crisis period.

\subsection{Variance Decomposition-Accounting National Stock Market Innovations}

The forecast error variance of each stock market can be allocated to sources by using orthogonalized innovations. For each market, the orthogonalization procedure provides the component of forecast error variance which is accounted for innovations in each of the six markets. Table 5 provides 
the decomposition of 10-days ahead of forecasts of the stock market returns into fractions that are accounted for by innovations of different markets.

Table 5 indicates that no national stock market is exogenous in that a market's own innovations fully account for its variance. On the contrary, a substantial amount of interaction is detected among national stock markets. At the horizon of 10-days, for example, the average percentage of error variance of a national stock market attributes to collective innovations in foreign stock markets during the four periods are 36.36, 43.91, and 45.04, respectively. During the financial crisis, as well as during the post-crisis period, the interactions among global markets were more active.

The results in Table 5 also indicate that the US stock market was the most influential in the world. While no single market can explain more than $3 \%$ of the US error variance, and even less than $0.4 \%$ during the crisis, the US explains an average of $48 \%$ of the German market error variance before, during, and after the crisis. The US stock market accounts for the greatest proportion of the foreign error variance for each of the other four stock markets. The other five markets have increased the error variance explained by US market innovations during the crisis period.

In the post-crisis period I, the error variance explained by foreign market for the US, UK, Germany, and China increase while, for Hong Kong and Japan, the numbers went down. The persistence of significant influence of the US market on the UK and German markets suggests that even after the crisis, UK and Germany relied to some extent on the recovery of the US economy and that they pay more attention to the US stock market even in the post-crisis period. Additionally, the European debt crisis continued and deepened as the financial crisis emerged in the US. This finding is in line with the higher correlation of residual returns in the post-crisis period of the US and Germany than during the crisis period.

Table 5. Accounting national stock market innovations.

\begin{tabular}{cccccccc}
\hline \multirow{2}{*}{ Market Explained } & \multicolumn{7}{c}{ By Innovations in } \\
\cline { 2 - 8 } & USA & UK & GERMANY & HONG KONG & JAPAN & CHINA & FM \\
\hline Panel (A) pre-crisis period: 14 June 2006-8 August 2007 & & & \\
\hline USA & 95.06 & 0.75 & 0.16 & 2.87 & 0.67 & 0.49 & 4.94 \\
UK & 38.39 & 58.59 & 1.22 & 1.36 & 0.12 & 0.33 & 41.41 \\
GERMANY & 41.71 & 34.11 & 22.45 & 0.70 & 0.89 & 0.15 & 77.55 \\
HONG KONG & 24.84 & 6.89 & 0.49 & 65.96 & 0.86 & 0.95 & 34.04 \\
JAPAN & 24.07 & 5.90 & 1.16 & 13.11 & 53.99 & 1.78 & 46.01 \\
CHINA & 3.10 & 0.61 & 1.78 & 8.26 & 0.43 & 85.82 & 14.18 \\
\hline Panel (B) crisis period: : 9 August 2007-6 March 2009 & & & & \\
\hline USA & 98.81 & 0.33 & 0.11 & 0.38 & 0.08 & 0.29 & 1.19 \\
UK & 45.95 & 52.24 & 0.73 & 0.79 & 0.07 & 0.20 & 47.76 \\
GERMANY & 48.64 & 30.57 & 20.29 & 0.27 & 0.13 & 0.10 & 79.71 \\
HONG KONG & 24.07 & 11.64 & 1.02 & 62.34 & 0.07 & 0.85 & 37.66 \\
JAPAN & 35.01 & 12.19 & 2.24 & 16.64 & 33.47 & 0.44 & 66.53 \\
CHINA & 6.17 & 3.45 & 0.58 & 16.83 & 3.55 & 69.42 & 30.58 \\
\hline Panel (C) post-crisis period I: 6 March 2009-21 July 2010 & & & & \\
\hline USA & 98.31 & 1.18 & 0.20 & 0.06 & 0.17 & 0.09 & 1.69 \\
UK & 53.85 & 42.00 & 3.97 & 0.05 & 0.08 & 0.06 & 58.00 \\
GERMANY & 55.13 & 26.56 & 18.15 & 0.03 & 0.07 & 0.05 & 81.85 \\
HONG KONG & 23.98 & 8.85 & 1.59 & 65.25 & 0.06 & 0.26 & 34.75 \\
JAPAN & 37.62 & 3.75 & 2.12 & 16.16 & 39.07 & 1.28 & 60.93 \\
CHINA & 7.38 & 1.73 & 2.93 & 20.89 & 0.08 & 67.00 & 33.00 \\
\hline
\end{tabular}

Note: Each entry in this table denotes the percentage of forecast error variance of the left-hand side market explained by the market at the top. Each entry in the last column, FM, of the table denotes the percentages of forecast error variance of the left-handed side market explained collectively by the "foreign" markets. 


\subsection{Dynamic Response Pattern}

The Granger causality provides information about whether innovation in one market affects a foreign market significantly. However, it gives no insight into the mechanism of international transmission of stock market movements as the intensity of the influence and the duration of the shock in a particular market. The pattern of dynamic responses of each of the six markets to innovations in the US market using the simulated responses of the estimated VAR system can provide such additional insight. To conserve space, this paper concentrates on the responses of each of the five markets to a shock in the US market. Table 6 provides normalized impulse responses of the five markets to a typical shock, i.e., positive residuals of one standard deviation unit in the US. To facilitate the interpretation of Table 6, time paths of the normalized impulse responses of the five markets to a US shock are shown in Figure A1.

Table 6. Impulse responses to the unit shock in the US market.

\begin{tabular}{ccccccc}
\hline \multirow{2}{*}{$i$ th Day of Shock } & \multicolumn{7}{c}{ Impulse Responses in } \\
\cline { 2 - 7 } & USA & UK & GERMANY & HONG KONG & JAPAN & CHINA \\
\hline Panel (A) pre-crisis period: 14 June 2006-8 August 2007 & & & \\
\hline 1 & 0.74 & 0.45 & 0.57 & 0.15 & 0.14 & 0.35 \\
2 & -0.07 & 0.19 & 0.25 & 0.50 & 0.49 & -0.07 \\
3 & -0.05 & -0.11 & -0.14 & -0.09 & -0.04 & -0.08 \\
4 & 0.00 & 0.01 & 0.01 & -0.04 & -0.04 & 0.04 \\
5 & 0.01 & 0.00 & 0.01 & 0.01 & 0.01 & 0.00 \\
\hline Panel (B) crisis period: 9 August 2007-6 March 2009 & & & \\
\hline 1 & 2.35 & 1.31 & 1.48 & 1.06 & 0.74 & 0.10 \\
2 & -0.48 & 0.62 & 0.39 & 1.00 & 1.30 & 0.64 \\
3 & -0.05 & -0.51 & -0.43 & -0.38 & -0.52 & -0.20 \\
4 & 0.06 & 0.20 & 0.18 & -0.03 & 0.02 & -0.05 \\
5 & -0.02 & -0.06 & -0.05 & 0.09 & 0.07 & 0.07 \\
\hline Panel (C) post-crisis period I: 6 March $2009-21$ July 2010 & & & \\
\hline 1 & 1.45 & 0.99 & 1.13 & 0.62 & 0.36 & 0.41 \\
2 & -0.05 & 0.14 & 0.25 & 0.65 & 0.90 & 0.27 \\
3 & 0.00 & -0.13 & -0.10 & -0.12 & -0.13 & -0.02 \\
4 & -0.02 & 0.02 & 0.02 & 0.02 & -0.01 & -0.01 \\
5 & 0.01 & -0.01 & -0.01 & -0.01 & 0.00 & 0.00 \\
\hline
\end{tabular}

Cholesky Ordering: USA, UK, GERMANY, HONG KONG, JAPAN, CHINA. Note: The $i, j$ th entry in this table represents the normalized impulse response of the $j$ th (column) market on the $i$ th day (row) to the unit shock in the US market. These entries are the estimates of moving average coefficients of the VAR system divided by their standard errors.

As can be seen from the examination of Figure A1 in the Appendix A, innovations in the US stock market are rapidly transmitted to all the other markets. UK and German markets respond to the US shock most dramatically on day 1 and, thereafter, the responses rapidly taper off. However, Hong Kong, Japan, and China present a different pattern of impulse responses. The responses of these three markets are sluggish in that the day 2 response is larger than day 1 . This is mainly because of different timing of markets; so the US's day 1 unit shock affects day 2 of these three markets. It can also be seen from Figure A1 that most of the adjustments of foreign stock prices to the US shock is completed by day 2 or day 3. This implies that it would be difficult to earn unusual profits by investing in a particular market based on the observed developments in other markets.

According to Figure A2 in the Appendix A, showing the accumulative response pattern, the financial crisis increases the influence of the US market unit shock on other markets. Additionally, according to Figure A2 in the Appendix A, showing the accumulative response pattern, the effect of the shock on other markets is long-term and does not disappear. 
According to Table 6, during the crisis period, the repercussion effect of one unit US shock significantly increases for each market. However, this new repercussion effect decreases after the crisis, but still remains larger than the pre-crisis level. This finding indicates that during the crisis, the risk of the US stock market increased dramatically.

Additionally, during the crisis, the impulse response of Hong Kong and Japan to the unit shock in the US market increased so intensely that the cumulative response in two days surpassed the impulse response of the US market to its own shock. This reflects the characteristic of export-oriented economies of these two markets. Hong Kong and Japan's economies are highly dependent on other markets. Their sensitivity levels to external shock are high.

\section{Conclusions}

The paper examines the co-movement of six major stock markets returns before, during and after the financial crisis of 2007-2008. For the analysis, we have applied vector auto-regression (VAR) model and conducted the Granger causality test.

The finding of results suggests that a substantial amount of interdependency exists among various stock markets during the financial crisis. Before the crisis, certain degree of interdependency witnessed among six leading stock markets; for example, feedback relationship was found between Hong Kong, USA, UK and Germany. Linkage among the five stock markets has increased sharply since the beginning of the crisis in August 2007. In particular, a drastic increase in the co-movements among USA and China, Germany and China, and UK and China were observed after the financial crisis.

Data confirmed that the correlation of stock markets between the United States, Britain, Germany, Japan and Hong Kong enhanced notably after the crisis, while it showed a reverse trend with the Chinese stock market. This conclusion is very consistent with the real world. As for Germany, Japan and Hong Kong, the impact of the crisis was stronger as they are more open economies. While for China, as the degree of openness is not high and the Chinese stock market was supervised by the government to a certain extent, therefore, the crisis has not much affected the economy as compared with the United States and other countries.

After the crisis, stock markets in developed countries gradually returned to normal position and the correlation between stock markets in developed countries and China is integrating further. The repercussion effect of unit shock in the U.S. market decreased, but was still higher than the pre-crisis level. After analyzing the dynamic responses of each of the six markets to innovations in a particular market, using the simulated responses of the estimated VAR system, it was noticeable that most of the responses to a shock were completed within three days. The results of impulse response also suggest that Hong Kong and Japan as finished-product export-oriented economies were greatly influenced by U.S. during the crisis.

The overall higher co-movement in global stock markets than in pre-crisis period may reflect that more common shocks were shared by these stock markets during the crisis: credit derivatives decreased in value, the housing price plummeted, exchange rate fluctuated and massive hedge funds were transferred globally. Furthermore, panics among individual investors also stimulated the co-movement of global stock markets. In addition, the dramatic increase of residual correlation between Japan and other markets is partly caused by the flight of Japanese hot money.

Overall, it can be concluded that the financial crisis reinforced the interdependence of the global markets. The co-movement and the interdependence have yet not fade away, though the co-movements of Hong Kong and Japan with other global markets have reduced after the crisis, the interdependence of other markets remains observable and even stronger in the post-crisis period.

Author Contributions: Yonghong Jiang designed the methodology and applied the model; Mengmeng Yu collected the data and reviewed the literature; Shabir Mohsin Hashmi analyzed the data and interpreted the results. All authors read and approved the final manuscript.

Conflicts of Interest: The authors declare no conflict of interest. 
Appendix

Response to Chobsky One SD. Innotions \pm 2 S.E. (pre-crisis period)

Response of USA to USA

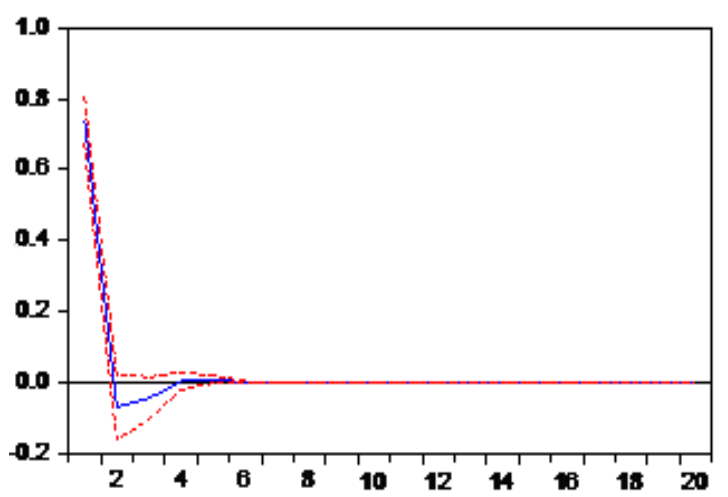

Response of GERuary to USA

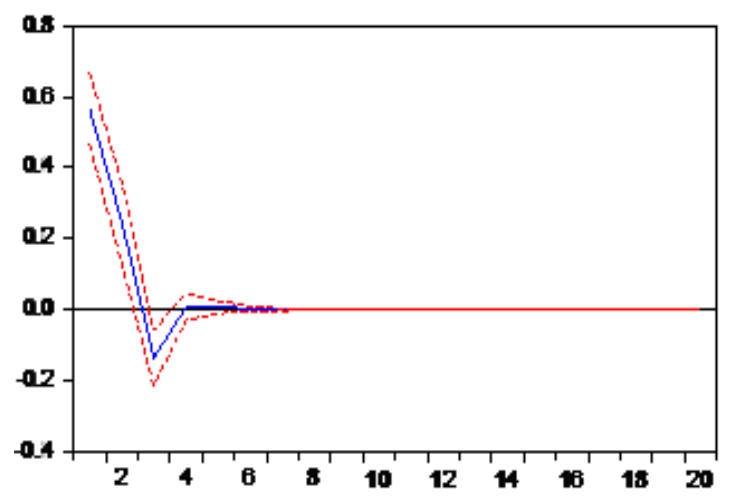

Response of JAPAN to USA

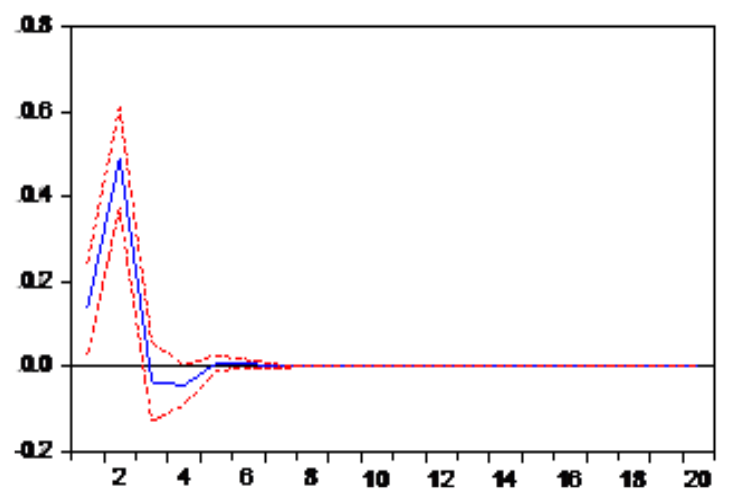

Response of UKto USA

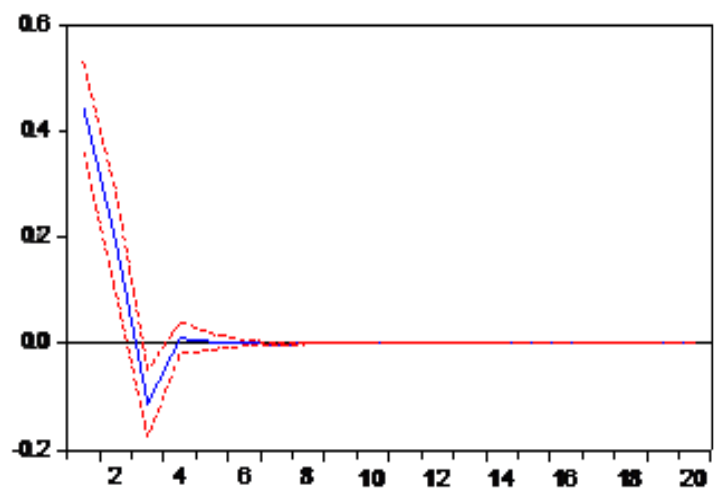

Response of HONG_KCNG to USA

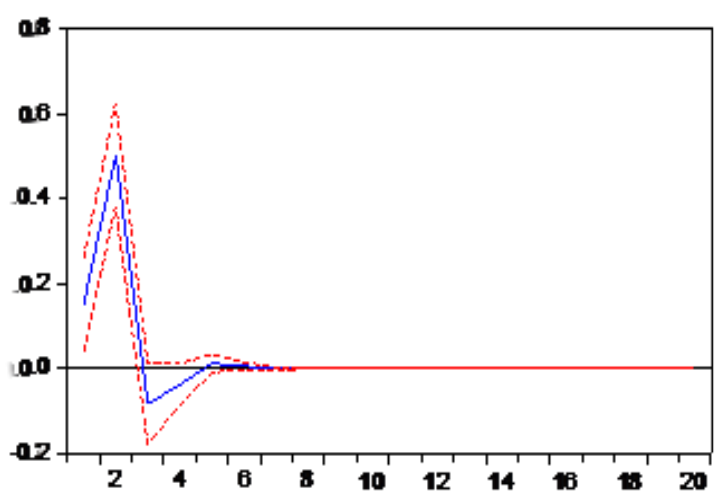

Response of GrinAto USA

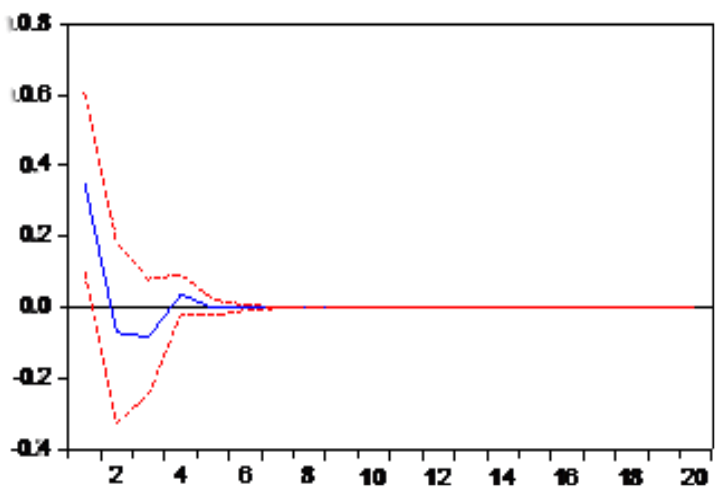

Figure A1. Cont. 
Response to Chobsky One S.D. Innowations \pm 2S.E. (crisis period)

Response of USA to USA

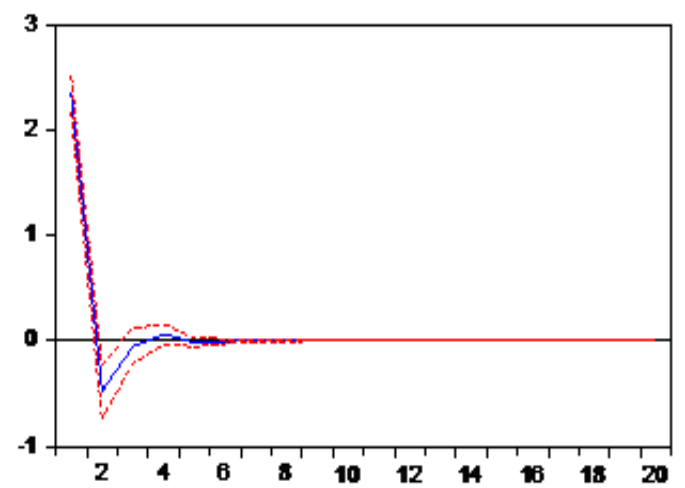

Response of GERuany to USA

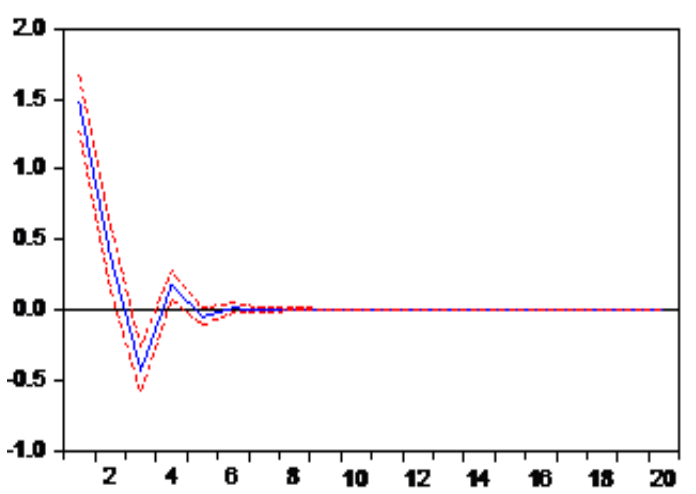

Response of JAPAN to USA

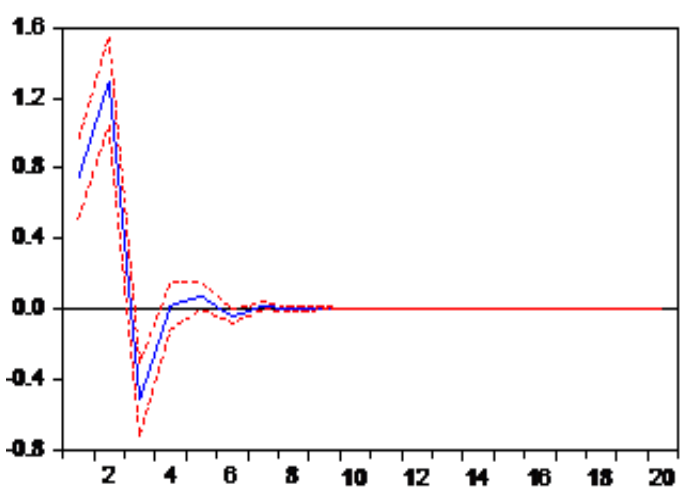

Response of UKto USA

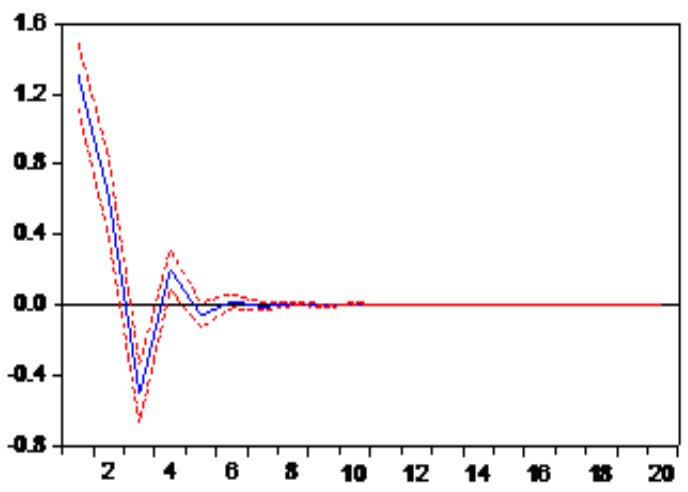

Response of HONG_KONG to USA

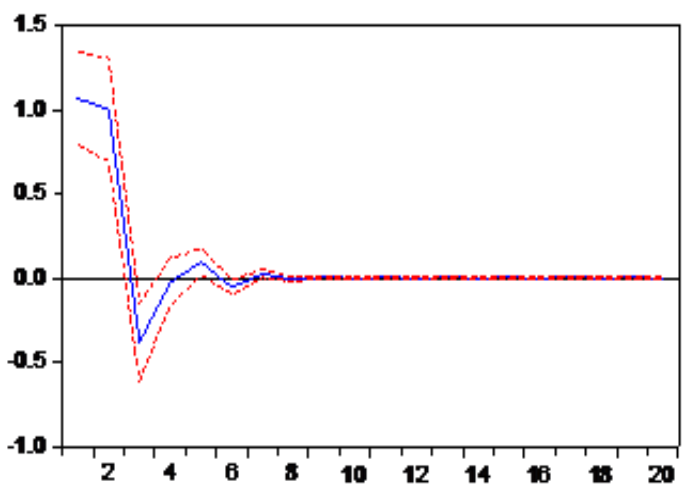

Response of GHAm USA

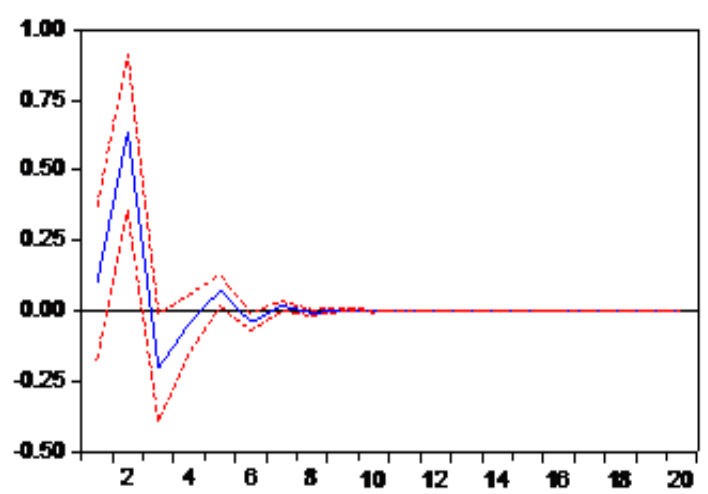

Figure A1. Cont. 
Responseto Cholesky One S.D. Inovationst2 S.E.(post-crisis period)

Response of USA to USA

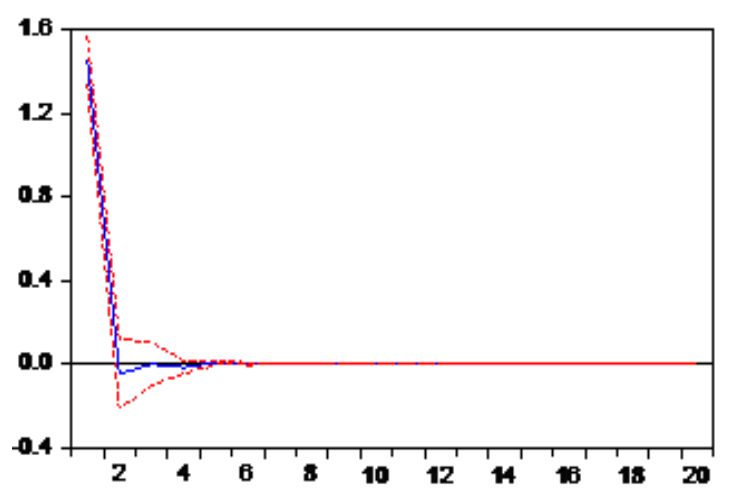

Response of GRinany to USA

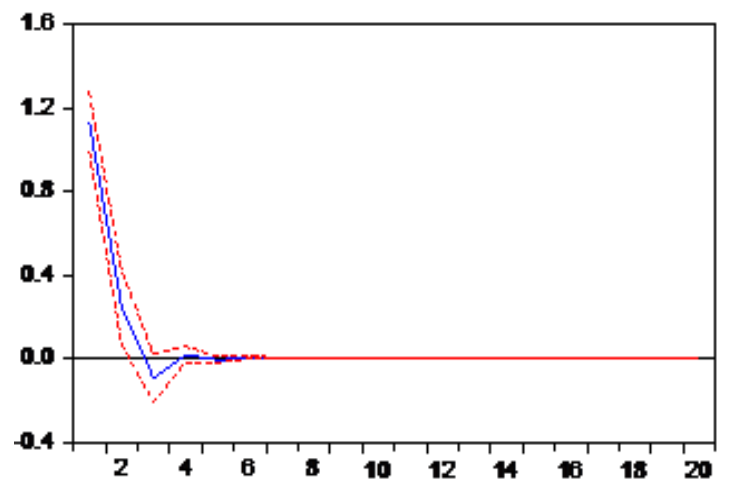

Response of JAPAN to USA

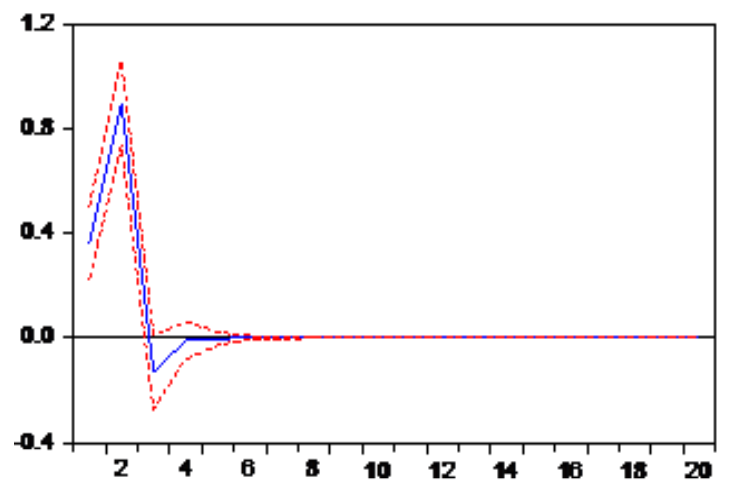

Response of UKto USA

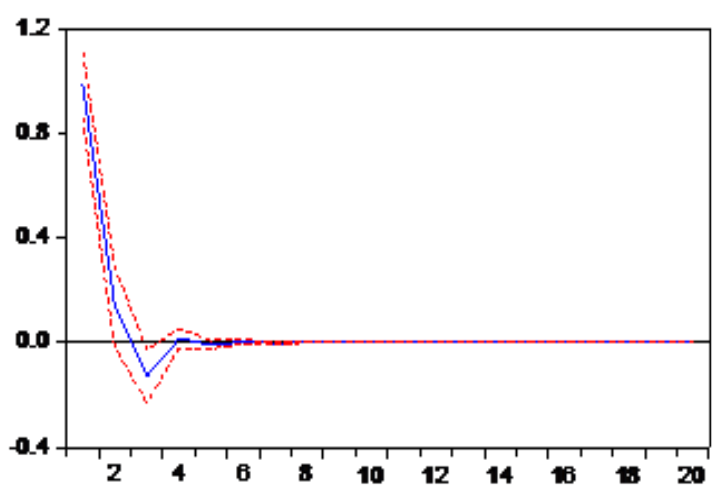

Response of HONG_KONG to USA

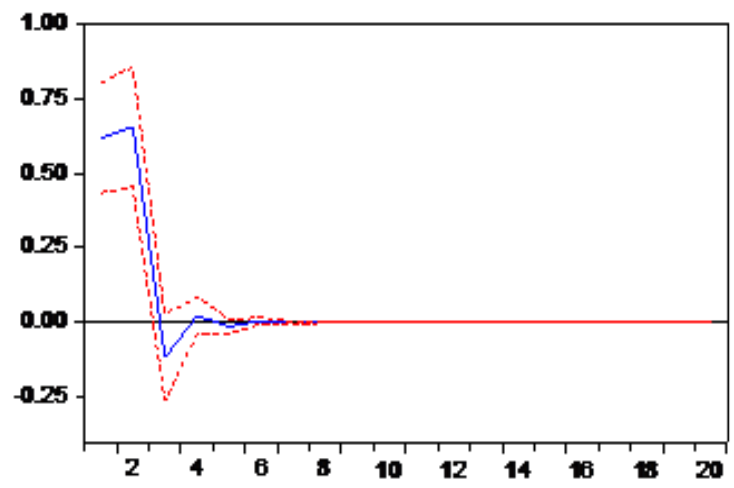

Response of GHAto USA

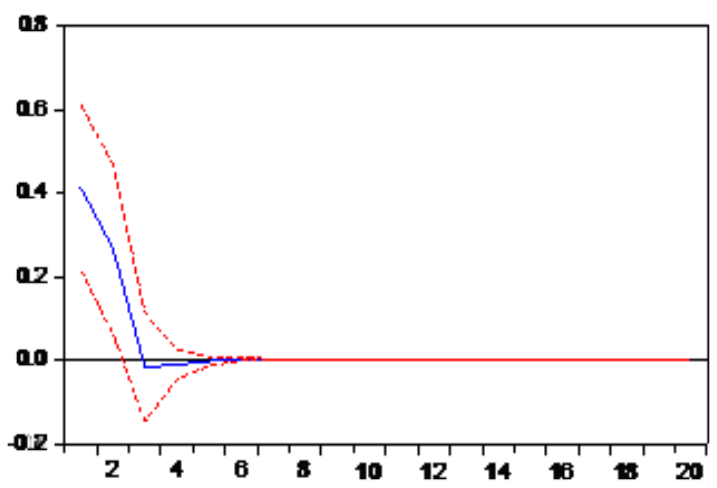

Figure A1. Impulse response among different countries. 
Aramulated Response to Chobsky One SD. Inovations(pre-crisis period)
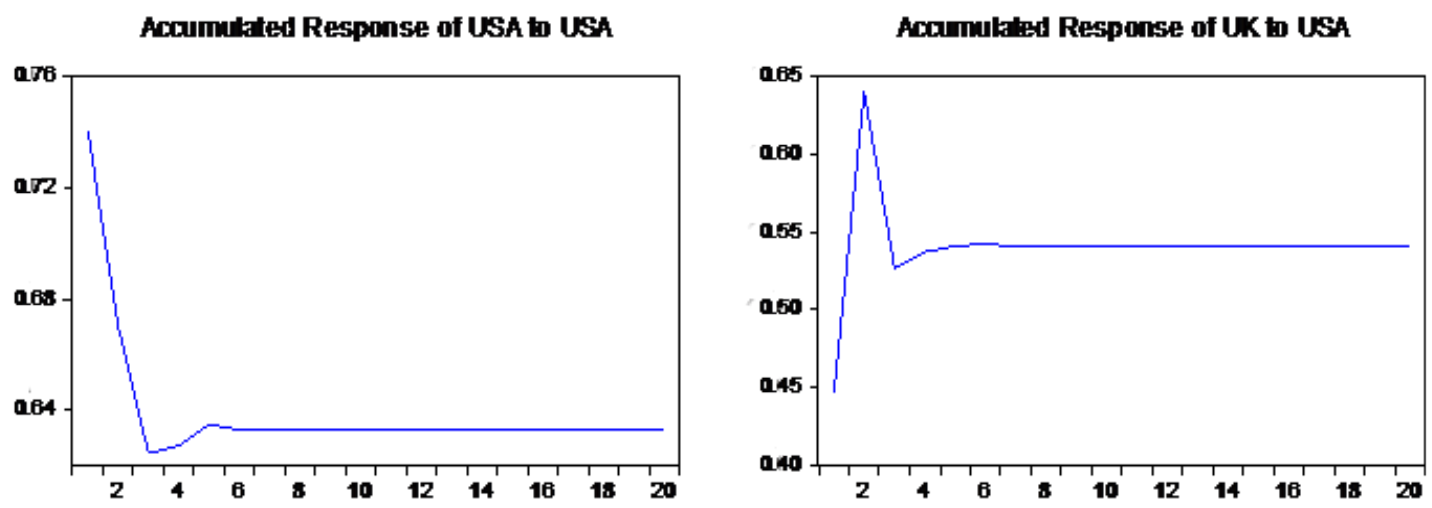

Accumulated Response of GRUANY to USA

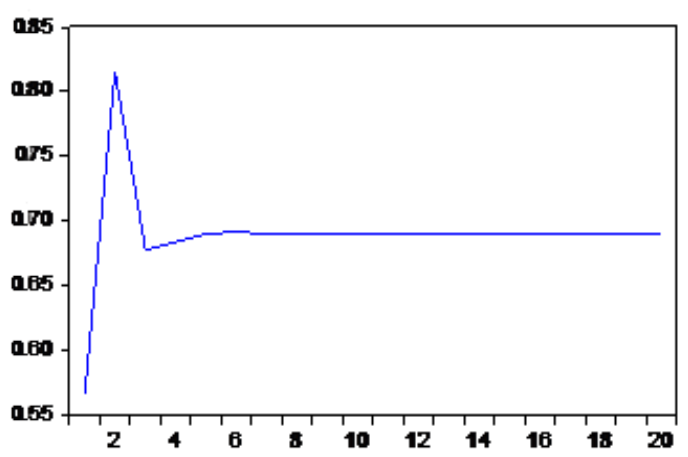

Accumulated Response of HONG_KONG to USA

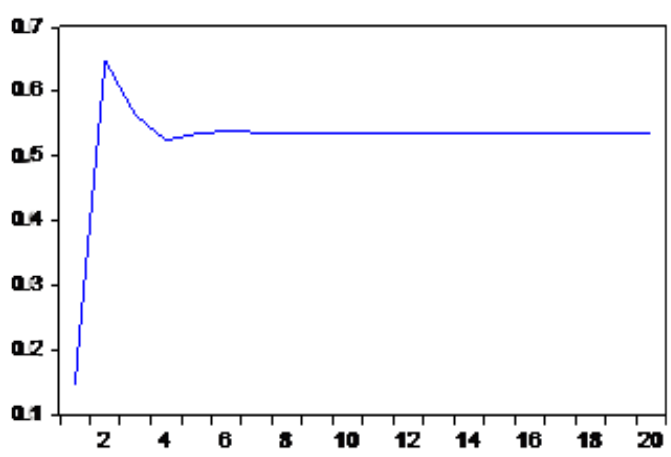

Accamutated Response of JAPAN to USA

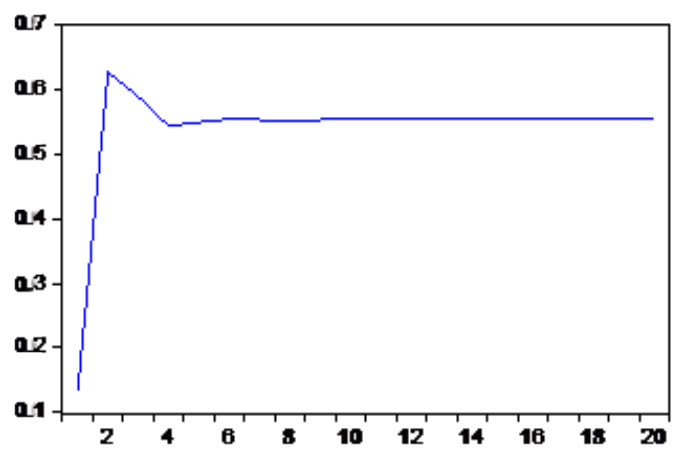

Accumulated Response of CHeNA to USA

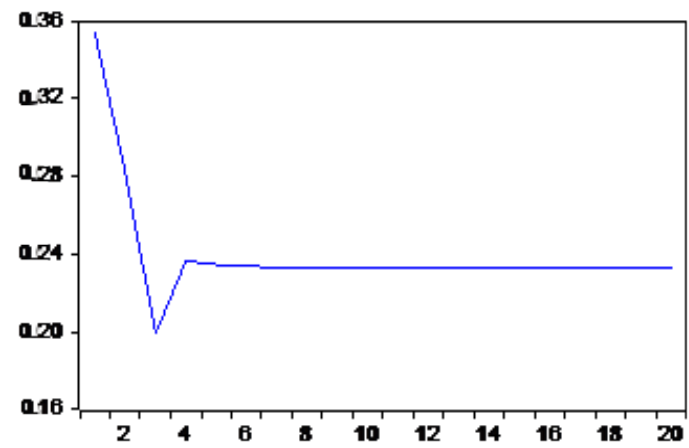

Figure A2. Cont. 
Acamulated Resporse to Cholesky One S.D. Innowations(crisis period))
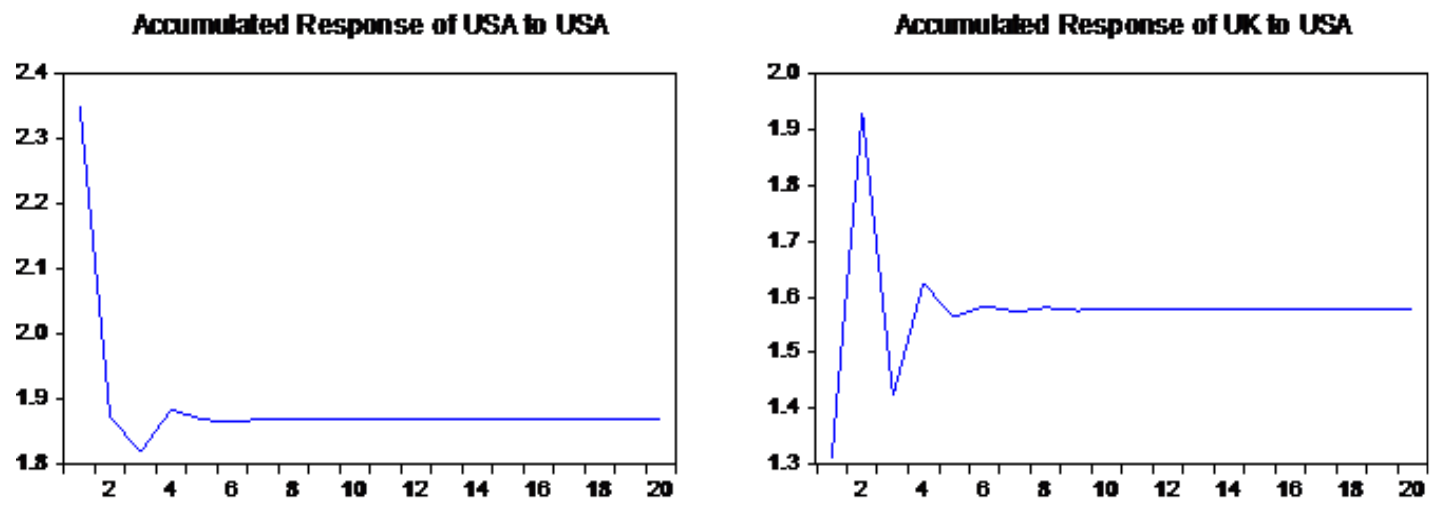

Accumulated Response of GRUANY to USA

Accumulated Response of HONG_KONG to USA
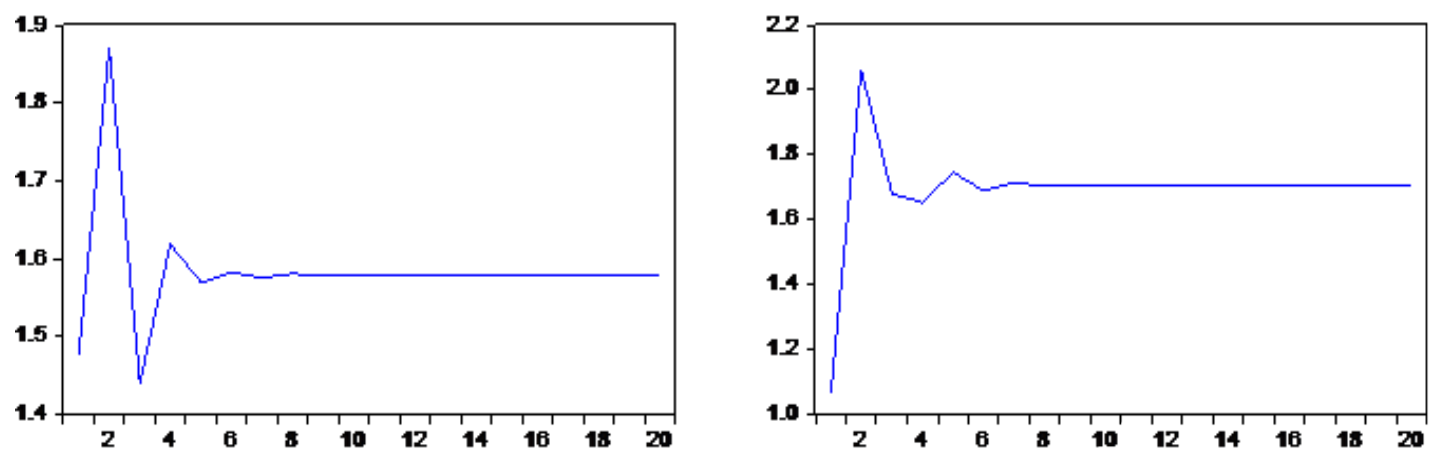

Accumulated Response of IAPAN to USA

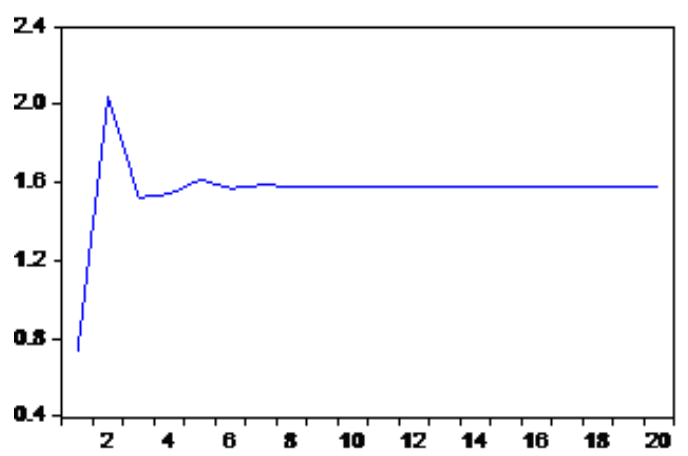

Accummated Response of CHENA to USA

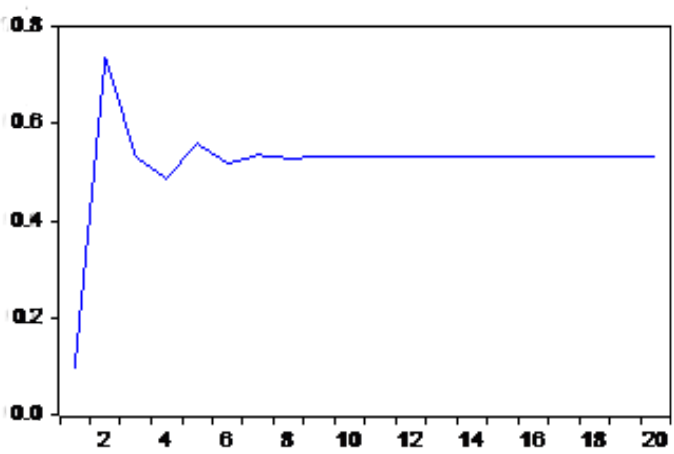

Figure A2. Cont. 
Response to Choksky One S.D. Innowations (post-risis period)

Response of USA buSA

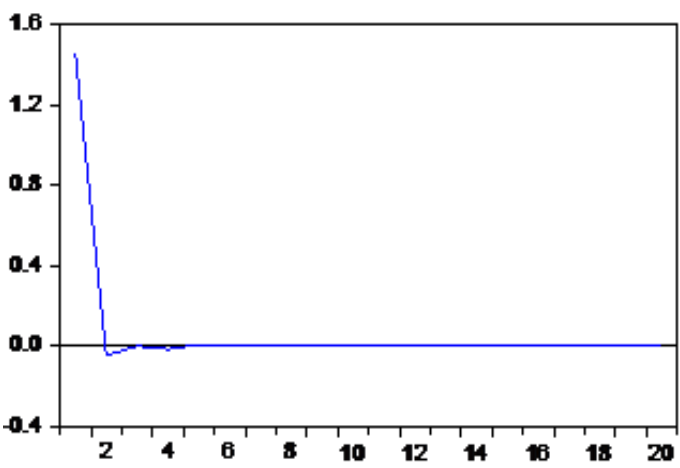

Response of GRuhy to USA

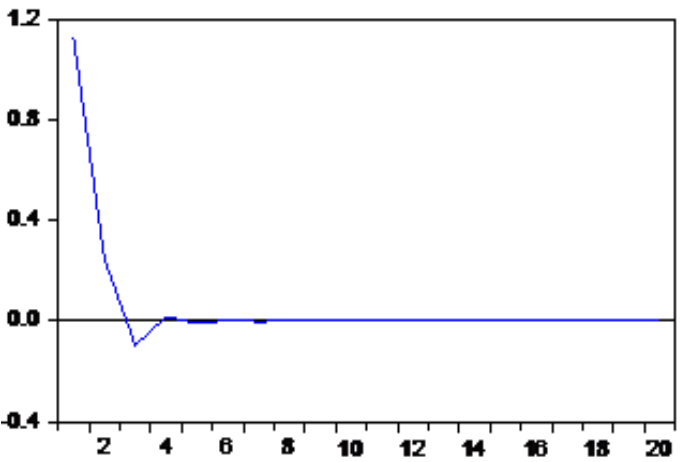

Recponse of JAPAN to USA

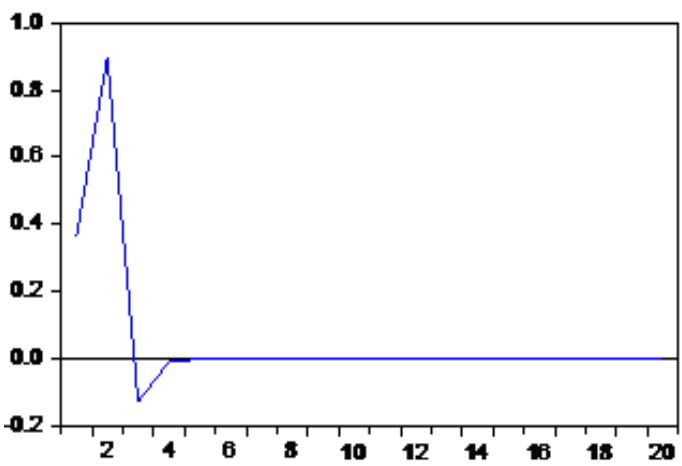

Response of UKm USA

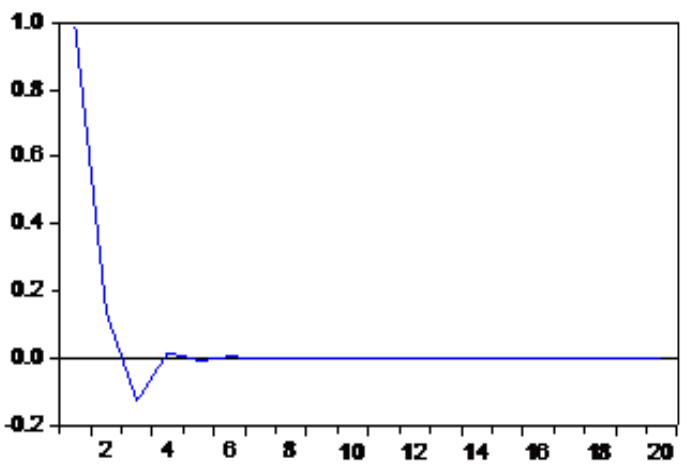

Response of HONG_KONG to USA

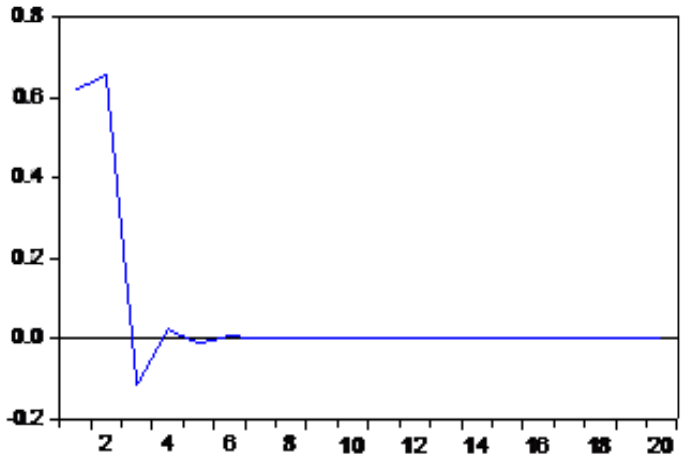

Response of Grento USA

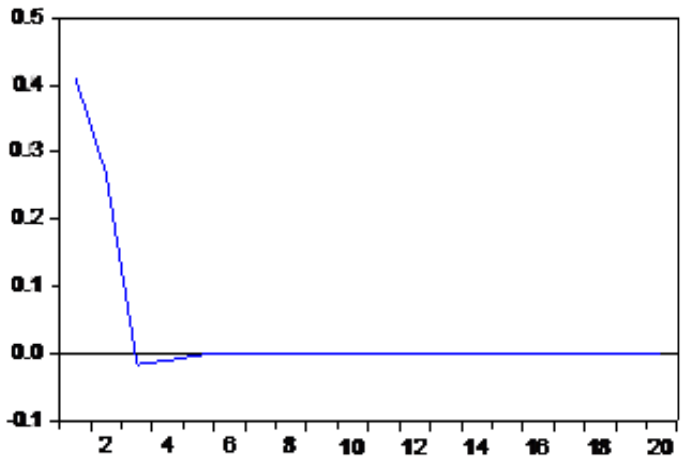

Figure A2. Accumulated response among different countries.

\section{References}

1. Michel, B.; Candelon, B. Liberalisation and stock market co-movement between emerging economies. Quant. Financ. 2011, 11, 299-312.

2. Liow, H.K. Co-movements and correlations across Asian securitized real estate and stock markets. Real Estate Econ. 2012, 40, 97-129. [CrossRef]

3. Granger, C.W.J. Investigating causal relations by econometric models and cross spectral methods. Ecomometrica 1970, 37, 424-438. [CrossRef]

4. Agmon, T. The relations among equity markets: A study of share price of co-movements in the United States, United Kingdom, Germany and Japan. J. Financ. 1973, 27, 839-855.

5. Hilliard, J. The relationship between equity indices on world exchanges. J. Financ. 1979, 34, $103-114$. [CrossRef] 
6. Malliaris, A.G.; Urrutia, J. The international crash of October 1987: Causality test. J. Financ. Quant. Anal. 1992, 27, 353-364. [CrossRef]

7. Ang, A.; Bekaert, G. Original Article International Asset Allocation with Regime Shifts. Rev. Financ. Stud. 2002, 15, 1137-1187. [CrossRef]

8. Alou, R.; Aïssa, M.S.B.; Nguyen, D.K. Global financial crisis, extreme interdependences, and contagion effects: The role of economic structure? J. Bank. Financ. 2011, 35, 130-141. [CrossRef]

9. Dajcman, S.; Festic, M.; Kavkler, A. European stock market co-movement dynamics during some major financial market turmoils in the period 1997 to 2010: A comparative DCC-GARCH and wavelet correlation analysis. Appl. Econ. Lett. 2012, 19, 1249-1256. [CrossRef]

10. Lee, G.; Jeong, J. Global Financial Crisis and Stock Market Integration between Northeast Asia and Europe. Rev. Eur. Stud. 2014, 6, 61-75. [CrossRef]

11. Liow, K.H.; Yang, H. Long-Term Co-Memories and Short-Run Adjustment: Securitized Real Estate and Stock Markets. J. Real Estate Financ. Econ. 2005, 31, 281-300. [CrossRef]

12. Celic, S. The more contagion effect on emerging markets: The evidence of DCC-GARCH model. Econ. Model. 2012, 29, 1946-1959. [CrossRef]

13. Klaassen, F. Improving GARCH volatility forecasts with regime-switching GARCH. Empir. Econ. 2002, 27, 363-394. [CrossRef]

14. Chang, T.; Li, X.L.; Miller, S.M.; Balcilar, M.; Gupta, R. The Co-Movement and Causality between the U.S. Real Estate and Stock Markets in the Time and Frequency Domains; Department of Economics, University of Pretoria: Pretoria, South Africa, 2012.

(C) 2017 by the authors; licensee MDPI, Basel, Switzerland. This article is an open access article distributed under the terms and conditions of the Creative Commons Attribution (CC BY) license (http:/ / creativecommons.org/licenses/by/4.0/). 